\title{
APLIKASI E-LEARNING UNTUK BIMBINGAN BELAJAR KUMON
}

\section{E-Learning Application for KUMON Tutoring}

\author{
Wendy Denata ${ }^{1}$, Honni ${ }^{1)}$ \\ ${ }^{1)}$ Sistem Informasi/Fakultas Teknologi dan Desain, Universitas Bunda Mulia \\ Diterima 07 Juni 2018 / Disetujui 31 Juli 2018
}

\begin{abstract}
Based on the results of the analysis, it is found that the learning process at PT. Mercantile Deodate is still not well organized, so it is designed a tutoring application that can help the learning process, information delivery and quiz work online to better assist the students, teachers, and people old in the learning process. The purpose of this study is to design the application of learning, quiz work, and provision of online development information based on web applications on PT. Mercantile Deodate to facilitate students and parents to do the learning process while in the tutoring and provide information on student development. The research method used in the preparation of this thesis is the method of collecting data through literature study. While the design method used is object-oriented method that includes use case diagrams, activity diagrams and class diagrams. With the application of this tutoring can simplify the process of providing learning materials, quizzes, and development information, especially Mathematics and English maximal.
\end{abstract}

Keywords: Tutoring Application, E-Learning, Information System.

\begin{abstract}
ABSTRAK
Berdasarkan hasil analisa, ditemukan bahwa proses belajar pada PT. Mercantile Deodate saat ini masih belum terorganisir dengan baik, sehingga dirancanglah sebuah aplikasi bimbingan belajar yang dapat membantu proses pembelajaran, penyampaian informasi serta pengerjaan kuis secara online agar lebih membantu para murid, guru, dan orang tua dalam proses belajar mengajar. Tujuan penelitian ini adalah untuk merancang aplikasi pembelajaran, pengerjaan kuis, dan pemberian informasi perkembangan secara online berbasis aplikasi web pada PT.Mercantile Deodate agar mempermudah murid dan orang tua untuk melakukan proses belajar saat berada di bimbingan belajar serta memberikan informasi perkembangan murid. Metode penelitian yang digunakan dalam penyusunan skripsi ini adalah metode pengumpulan data melalui studi pustaka. Sedangkan metode perancangan yang digunakan adalah metode berorientasi objek yang mencakup use case diagram, activity diagram dan class diagram. Dengan adanya aplikasi bimbingan belajar ini dapat mempermudah proses pemberian materi pembelajaran, kuis, dan informasi perkembangan, terutama Matematika dan Bahasa Inggris lebih maksimal.
\end{abstract}

Kata Kunci: Aplikasi Bimbingan Belajar, E-Learning, Sistem Informasi. 


\section{PENDAHULUAN}

Seiring dengan perkembangan Teknologi Informasi yang semakin pesat, kebutuhan akan suatu konsep dan mekanisme belajar mengajar berbasis TI menjadi tidak terelakkan lagi. Konsep yang disebut Sistem Informasi ini membawa pengaruh pada proses pendidikan konvensional menjadi digital. Saat ini konsep Sistem Informasi sudah banyak diterima oleh masyarakat dunia, terbukti dengan banyaknya implementasi Sistem Informasi pada lembaga pendidikan.

PT. Mercantile Deodate atau yang disebut sebagai Kumon, yang ingin mengutamakan membantu siswa dalam mengembangkan kemampuan dasar akademik yang kuat dan mampu menjadi orang-orang yang belajar secara mandiri, dan dalam pengembangan ilmu pengetahuan khususnya di bidang Teknologi Informasi. Selama ini proses belajar di Kumon masih bersifat di dalam kelas untuk mengadakan test, dan di rumah untuk mempelajari materi yang diberikan.

Saat ini Kumon belum mempunyai sarana untuk mengelola dan memudahkan dalam siswa mendapatkan materi baru saat mereka di rumah, dan juga memudahkan interaksi antara guru dan orang tua siswa agar dapat melihat perkembangan anaknya dalam proses belajar.

Sistem Informasi ini diperlukan untuk mempermudah siswa dalam mendapatkan materi dan berinteraksi dengan guru. Dan juga membantu orang tua siswa agar bisa mendapatkan informasi tentang perkembangan anaknya. Dengan pembelajaran secara online, para siswa akan lebih didorong untuk lebih mandiri dalam proses belajar, tetapi juga di pantau oleh guru saat mereka berada dalam kelas. Begitu juga dengan membuatnya menjadi web base, pada orang tua juga dapat melihat bagaimana perkembangan anaknya dalam proses belajar tersebut.

*Korespondensi Penulis:

E-mail: wendydenata@gmail.com

\section{STUDI PUSTAKA}

\section{E-Learning}

Menurut Ruth Colvin Clark dan Richard E. Mayer (2011, p8), e-Learning di definisikan sebagai instruksi disampaikan pada perangkat digital seperti komputer atau perangkat mobile yang ditujukan untuk mendukung pembelajaran.

\section{SDLC Waterfall}

Menurut Suryantara (2014,p6) dalam buku Merancang Aplikasi Akuntansi dengan VB.Net, bila menggunakan tahapan Waterfall untuk pembuatan atau pengembangan sistem setiap tahapn harus diselesaikan terlebih dahulu secara tuntas, sebelum melanjutkan ketahapan berikutnya. Hal ini bertujuan untuk menghindari terjadinya pengulangan pada tahapan tersebut. Secara umum pendekatan waterfall cenderung lama karena tahapan berikutnya tidak bisa bekerja sebelum tahapan sebelumnya selesai dengan tuntas, namun memiliki ketelitian pada setiap tahapan yang dilalui.

\section{Unified Modelling Language (UML)}

UML adalah sebuah kumpulan standar dari teknik pembuatan diagram yang menyediakan sebuah representasi grafis yang cukup kaya untuk memodelkan banyak sistem pengembangan proyek dari analisis menuju implementasi (Tegarden, Dennis \& Wixom, 2013).

Namun demikian model-model itu dapat dikelompokkan berdasarkan sifatnya yaitu statis atau dinamis. Jenis diagram itu antara lain: (Herlawati \& Widodo, 2011)

11.Use Case Diagram untuk memodelkan proses bisnis.

12.Conceptual Diagram untuk memodelkan konsep-konsep yang ada di dalam aplikasi.

13.Sequence Diagram untuk memodelkan pengiriman pesan (message) antar objek.

14.Collaboration Diagram untuk memodelkan interaksi antar objek.

15.State Diagram untuk memodelkan perilaku objects di dalam sistem.

16.Activity Diagram untuk memodelkan perilaku Use Case dan objek di dalam sistem. 
17.Class Diagram untuk memodelkan struktur kelas.

18.Object Diagram untuk memodelkan struktur objek.

19.Component Diagram untuk memodelkan komponen objek.

20.Deployment Diagram untuk memodelkan distribusi aplikasi.

\section{Entity Relationship Diagram (ERD)}

Database relasional didasarkan pada koleksi tabel dengan setiap tabel yang memiliki primary key - field atau fields yang nilainya unik untuk setiap baris tabel. tabel saling terkait satu sama lain dengan menempatkan primary key dari satu tabel ke dalam tabel terkait sebagai foreign key (Tegarden, Dennis \& Wixom, 2013).

Yii

Menurut David Naista (2016), Yii adalah framework PHP berbasis-komponen dan berkinerja tinggi untuk pengembangan aplikasi web berskala-besar. Yii menyediakan reusability maksimum dalam pemrograman Web dan mampu meningkatkan kecepatan pengembangan secara signifikan.

\section{MariaDB}

MariaDB adalah DBMS yang bersifat open soruce dan dikembangkan oleh pengembang yang sama dari MySQL. MySQL sendiri merupakan DBMS yang sudah sangat populer digunakan dan saat ini telah diakuisisi oleh perusahaan Oracle. Perkembangan MariaDB terbilang sangat cepat bila dibandingkan dengan DBMS lain yang sama-sama bersifat open source. Saat ini MariaDB telah digunakan lebih dari 12 juta pengguna di dunia, termasuk perusahaan-perusahaan besar seperti booking.com, HP, Virgin Mobile and Wikipedia (MariaDB, 2014b).

\section{Cascading Style Sheet (CSS)}

Menurut Priyanto Hidayatullah dan Jauhari Khairul Kawistara (2014), Cascading Style Sheet (CSS) digunakan untuk mengatur format tampilan pada halaman web agar rapi, dinamis, dan menarik.

Ada 4 cara memasang kode CSS ke dalam kode HTML, yaitu:
1. Inline Style Sheet (Memasukkan kode CSS langsung pada tag HTML)

2. Internal Style Sheet (Embed atau memasang kode CSS ke dalam bagian $<$ head $>$ )

3. Melakukan link ke external CSS

4. Import CSS file

\section{Referensi Penelitian Terdahulu}

Penelitian pertama yang pernah dilakukan oleh Maya Silvi Lydia, Dian Wirdasari, Siti Dara Fadilla (2015) yang berjudul "Pengembangan Metode Pembelajaran Inovatif Berbasis Web menggunakan e-Learning". Metode penelitian yang digunakan adalah metode pelaksanaan yang terdiri dari memberikan solusi yang ditawarkan, dan metode pendekatan.

Penelitian kedua yang pernah dilakukan oleh Canggih Ajika Pamungkas (2015) yang berjudul "Rancang Bangun ELearning Center Berbasis Web Untuk Meningkatkan Kualitas dan Kuantitas Media Pembelajaran Yang Efektif'. Tujuan Penelitian adalah menghasilkan media pembelajaran berupa e-learning center berbasis web untuk menciptakan media pembelajaran yang menarik, efektif dan efisien waktu sehingga hasil yang akan dicapai mahasiswa lebih mudah mendapatkan dan berbagi materi kuliah.

\section{METODOLOGI PENELITIAN} berikut:

Metode pemgumpulan data sebagai

1. Metode Observasi

Melakukan pengamatan yang dilakukan dengan mengunjungi lokasi dari kumon tersebut.

2. Metode Wawancara

Melakukan tanya jawab kepada owner agar hasil dari penelitian ini dapat membantu menyelesaikan masalah yang terjadi.

3. Metode Studi Pustaka

Mengumpulkan data dari berbagai jenis buku, jurnal, artikel dan literatur lainnya yang akan digunakan sebagai landasan teori. 


\section{Langkah-Langkah Penelitian}

Peneliti menggunakan langkah dibawah ini untuk mengembangkan seluruh hasil penelitian:



Gambar 1. Langkah-Langkah Penelitian

Namun demikian model-model itu dapat dikelompokkan berdasarkan sifatnya yaitu statis atau dinamis. Jenis diagram itu antara lain:

1. Tahap pertama: peneliti melakukan 3 metode pengumpulan data yang digunakan untuk menyelesaikan penelitian ini, yaitu studi pustaka, wawancara dan observasi.

2. Tahap kedua: peneliti mulai melakukan penelitian dengan analisis data berupa perancangan dengan bantuan metode seperti flowchart, UML dan ERD sebagai dasar perancangan aplikasi ini.

3. Tahap ketiga: peneliti melakukan pengkodean yang telah dirancangan pada tahap sebelumnya dengan menggunakan bahasa pemogramman PHP dan database MySQL.

4. Tahap keempat: peneliti melakukan proses implementasi pada objek penelitian dan menjalankan proses percobaan pada aplikasi, dan menentukan apakah aplikasi sudah sesuai dengan perancangan.

5. Tahap kelima: peneliti menutup penelitian ini dengan menarik kesimpulan dan saran dari hasil penelitian ini.

\section{Usecase}

Berikut ini adalah gambar usecase untuk aplikasi kumon ini:

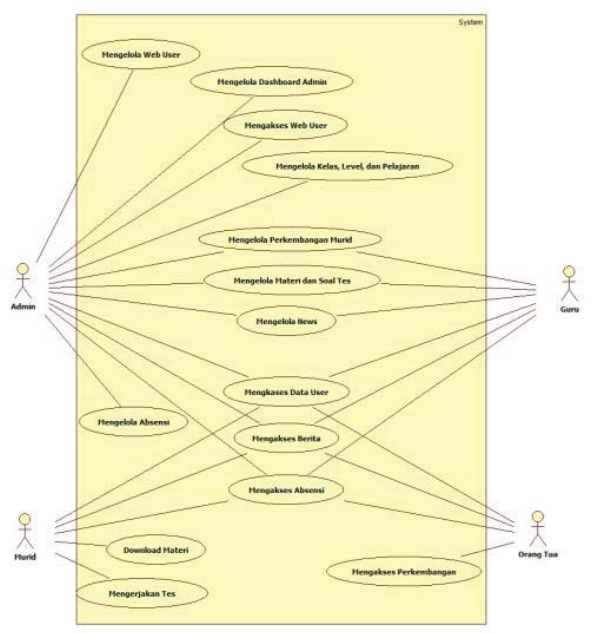

Gambar 2. Usecase

\section{Activity Diagram}

Berikut ini adalah gambar activity diagram sistem berjalan di Kumon.

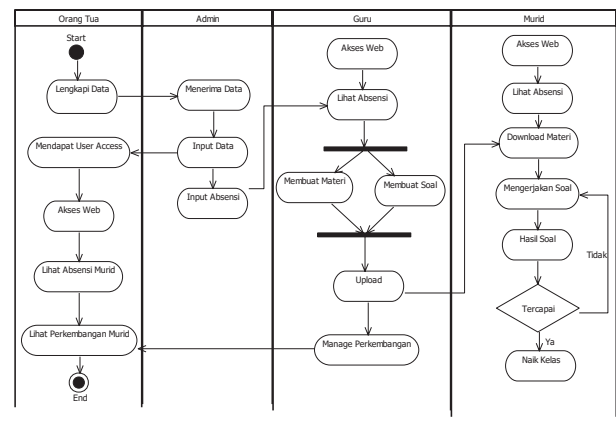

Gambar 3. Activity Diagram

\section{Class Diagram}

Berikut ini adalah gambar class diagram untuk aplikasi e-learning kumon: 


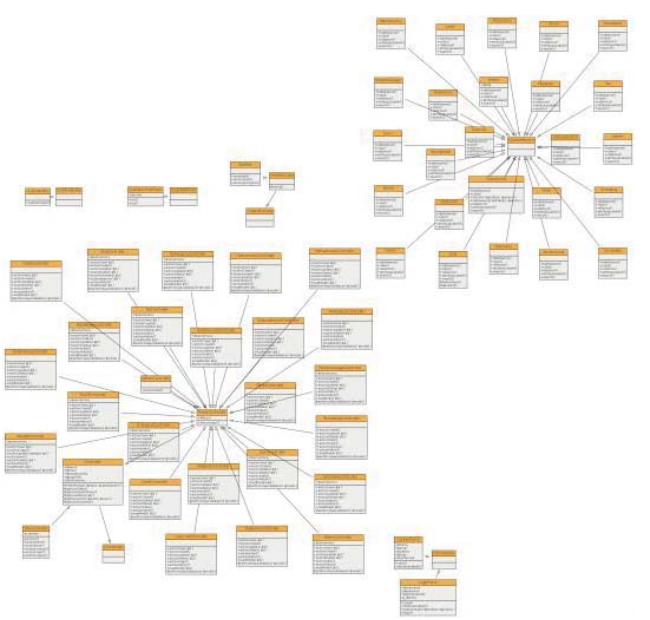

Gambar 4. Class Diagram

\section{Entity Relationship Diagram (ERD)}

Berikut ini adalah gambar entity relationship diagram untuk aplikasi $e$ learning ini:

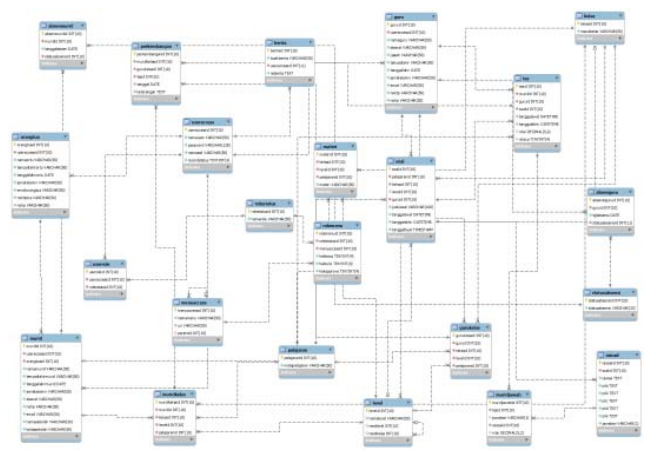

Gambar 5. Entity Relationship Diagram

\section{Analisa Perancangan}

Berikut ini adalah perancangan desain pada aplikasi e-learning ini:

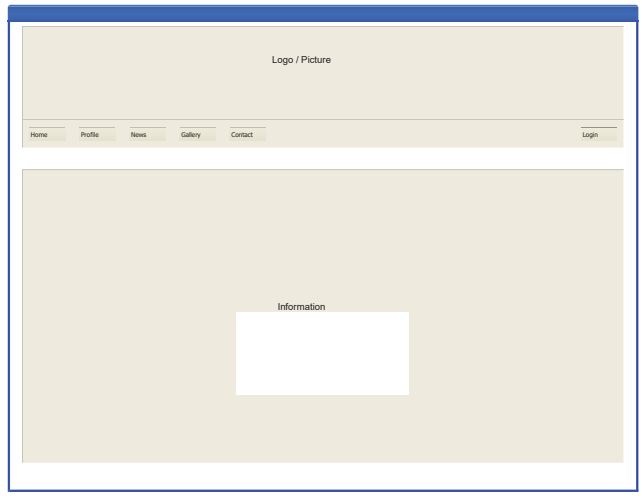

Gambar 6. Halaman Menu Utama

Tampilan menu utama atau menu utama ini tersedia 6 tombol home, profilem news, gallery, contact, dan login.

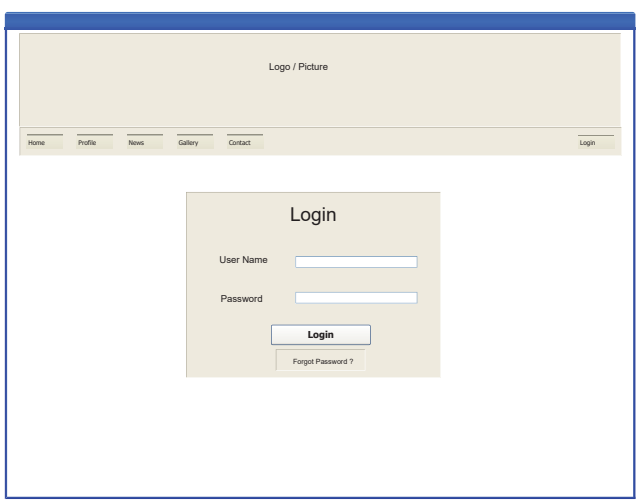

Gambar 7. Halaman Login

Pada tampilan menu login ini muncul tampilan untuk murid masuk ke halaman backend.

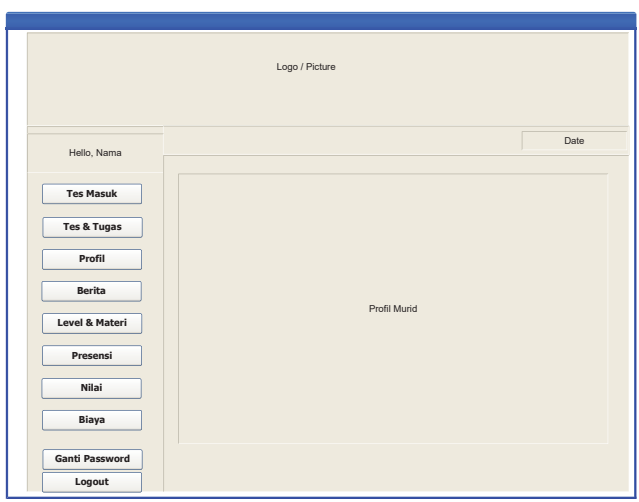

Gambar 8. Halaman Data Murid

Tampilan ini berisikan kotak teks dan data-data murid.

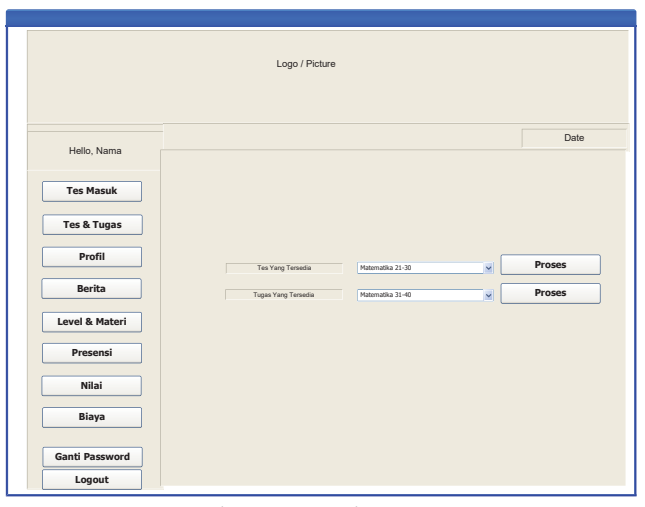

Gambar 9. Halaman Tes

Tampilan menu Tes isinya adalah tampilan awal sebelum murid melakukan Tes. 


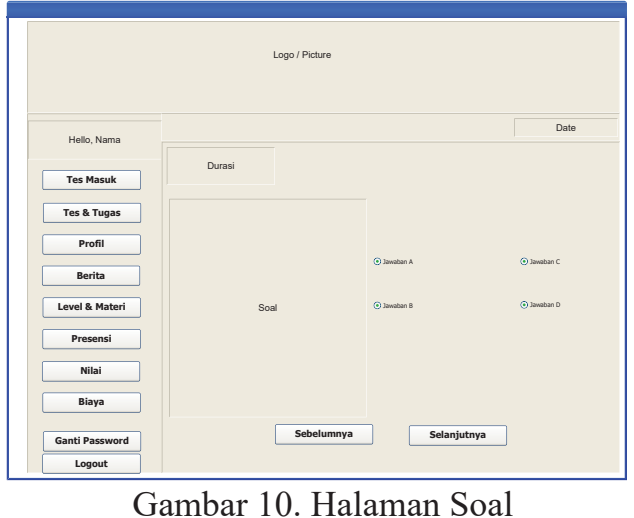

Menu soal ini adalah halaman bagi murid untuk mengerjakan soal yang diberikan.

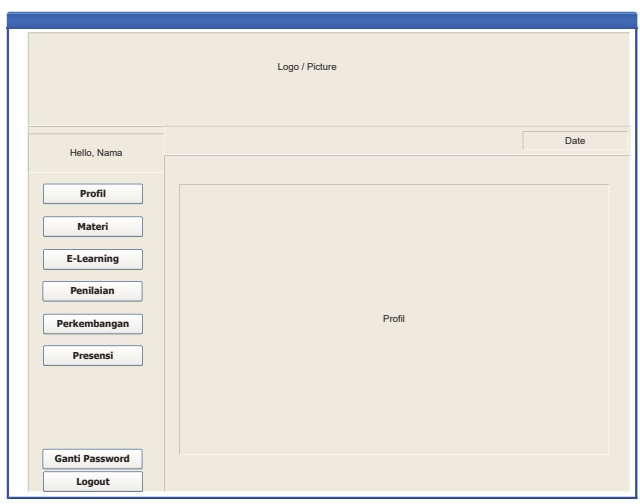

Gambar 11. Halaman Profile Guru

Menu untuk memberikan informasi data-data guru setelah guru login.

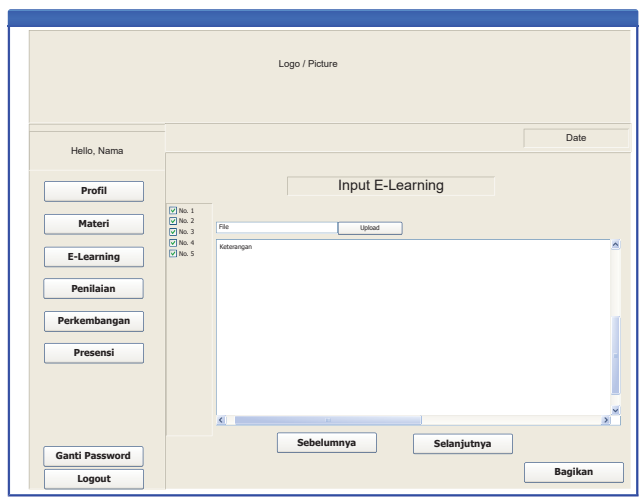

Gambar 12. Halaman Input Soal

Halaman bagi guru untuk membuat soal-soal yang akan diberikan kepada murid.

\section{HASIL DAN PEMBAHASAN}

\section{Hasil Tampilan}

Berikut ini adalah hasil tampilan desain pada aplikasi e-learning ini:

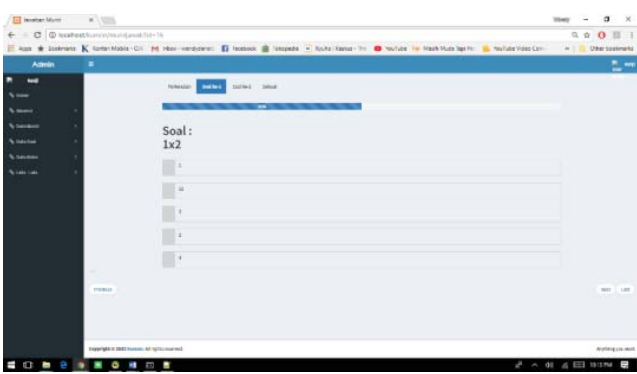

Gambar 13. Tampilan Mulai Tes

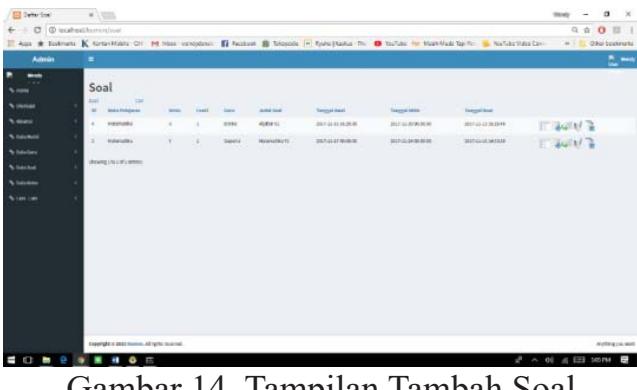

Gambar 14. Tampilan Tambah Soal

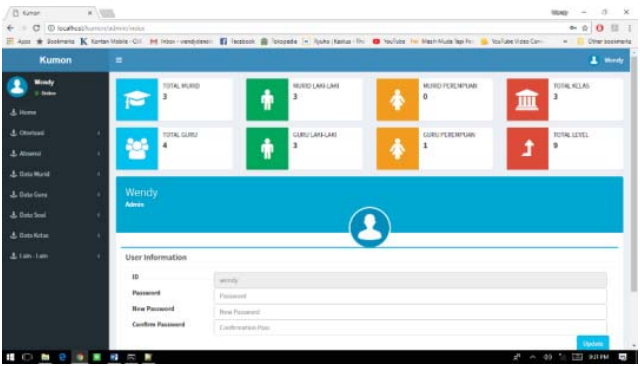

Gambar 15. Tampilan Admin

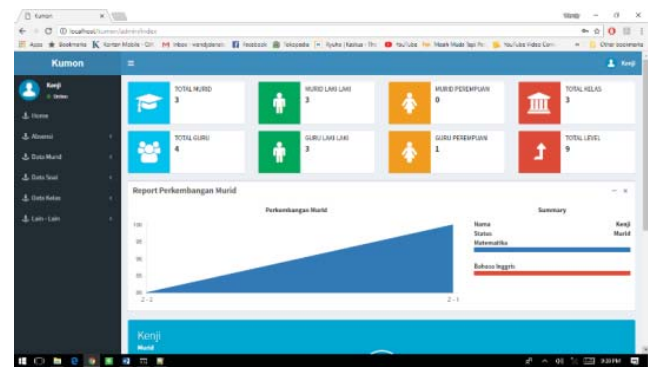

Gambar 16. Tampilan Data Siswa

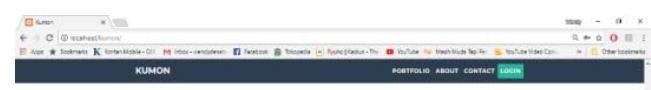

LOGIN
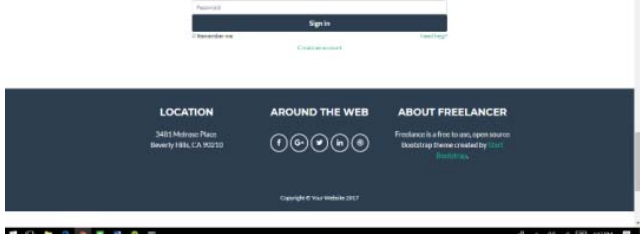

Gambar 17. Tampilan Login 


\section{KESIMPULAN DAN SARAN}

\section{Kesimpulan}

Setelah melakukan perancangan Aplikasi E-Learning untuk Bimbingan belajar Kumon pada PT. Mercantile Deodate, maka disimpulkan bahwa aplikasi kumon dapat membantu para murid agar mendapatkan materi pada saat mereka dirumah. Dan juga dapat memberikan kemudahan bagi orang tua untuk melihat perkembangan anaknya.

\section{Saran}

Setelah melakukan perancangan Aplikasi Bimbingan Belajar Kumon pada PT. Mercantile Deodate, jika ingin melakukan pengembangan sistem ke tahap selanjutnya. Maka adapun beberapa saran yang harus diperhatikan, yaitu:

1. Tampilan situs harus lebih user friendly agar para murid dapat lebih mudah mengerti.

2. Menambahkan fitur bagian keuangan dalam sistem informasi kumon tersebut.

3. Menambahkan fitur sekuritas pada website yang akan dihosting nanti.

\section{DAFTAR PUSTAKA}

Clark, Ruth Colvin dan Mayer, Richard E. .2011. E-Learning and the Science of Instruction, Third Edition, John Wiley \& Sons, Inc., USA.

Hidayatullah, Priyanto dan Kawistara, Jauhari Khairul. 2014. Pemrograman WEB, Informatika Bandung, Bandung.

Maya, Lydia Silvi, Wirdasari, Dian, dan Fadilla, Siti Dara. 2015. Pengembangan Metode Pembelajaran Inovatif Berbasis Web menggunakan e-Learning. Sumatera Utara.

MariaDB. 2014. About MariaDB. Tersedia di: https://mariadb.org/about/ [Diakses Januari 12, 2017].

Naista, David. 2016. Bikin Framework $P H P$ Sendiri dengan $O O P \& M V C$, Lokomedia, Yogyakarta.
Pamungkas Ajika Canggih. 2015. Rancang Bangun E-Learning Center Berbasis Web Untuk Meningkatkan Kualitas dan Kuantitas Media Pembelajaran Yang Efektif. Surakarta.

Suryantara, I Gusti Ngurah (2014), Merancang Aplikasi Akuntansi Dengan VB.Net Elex Media Komputindo, Jakarta. 